\title{
Needle-stick injuries in the National Health Service: a culture of silence
}

\author{
B Elmiyeh MRCS $^{1}$ I S Whitaker MA MB ${ }^{1} \quad M$ J James FRCS FRCS (Plast) ${ }^{2}$ C A A Chahal MB BSc ${ }^{5}$ \\ A Galea MD AFRCS(Ed) ${ }^{3} \quad$ K Alshafi FRCPath ${ }^{4}$
}

J R Soc Med 2004;97:326-327

\section{SUMMARY}

Injury by contaminated sharp instruments and needles constitutes a major occupational hazard for healthcare workers. In a confidential survey at a district general hospital, $\mathbf{3 0 0}$ healthcare professionals were asked about their personal experience of needle-stick injury and their attitudes to reporting.

279 individuals responded, of whom $38 \%$ had experienced at least one needle-stick (mean 1.8) in the past year and $74 \%$ had sustained such an injury during their careers (mean 3.0). Although $80 \%$ of respondents were aware that such incidents should be notified, only $51 \%$ of those affected had reported all needle-stick injuries. Doctors were less likely to report than nurses, despite a higher liability to injury.

This survey adds to evidence of a culture of silence pertaining to needle-stick injuries. The consequent risks to health, and the ethical and financial implications, remain uncertain.

\section{INTRODUCTION}

The National Audit Office report A Safer Place to Work ${ }^{1}$ highlighted the risk to National Health Service (NHS) staff posed by contaminated 'sharps'. Needle-stick injuries are the second most commonly reported adverse incident within the NHS (17\%), and constitute a major hazard for the transmission of viral disease - hepatitis $\mathrm{B}$ and $\mathrm{C}$ and HIV. They are also a potential source of transmission of prion diseases. The risk of transmission of hepatitis $\mathrm{C}(3 \%)$, hepatitis B (30\%), and HIV (0.3\%) from the patient to the healthcare worker depends on the viral load of the patient and the amount of blood that passes from one to the other. ${ }^{2-4}$ The prevalence of these viruses in the hospital patient population and in healthcare workers is uncertain. We conducted a survey of exposure to such injuries and of reporting practices in a district general hospital.

\section{METHODS}

The Lister Hospital, Stevenage, is a 512-bedded acute district general hospital within the East \& North Hertfordshire Trust providing a full range of core NHS services. A report by the Commission for Health Improvement had praised the Trust for worthwhile progress

${ }^{1}$ Department of Anatomy, University of Cambridge; Departments of ${ }^{2}$ Plastic and ${ }^{3}$ Orthopaedic Surgery and ${ }^{4}$ Department of Microbiology, Lister Hospital, Stevenage; ${ }^{5}$ Department of Surgery, Leeds General Infirmary, Leeds, UK Correspondence to: Dr I S Whitaker, 3 Magellan House, Armouries Way, Leeds LS10 1JE, UK in clinical risk management, at both strategic and operational levels. A confidential questionnaire (available from authors) was posted between October 2002 and May 2003 to 300 healthcare professionals in clinical work (175 nurses, 125 doctors).

\section{RESULTS}

$279(93 \%)$ of the 300 questionnaires were completed correctly. In total, 158 (57\%) of the 279 respondents had sustained one or more needle-stick injuries in their careers, $115(38 \%)$ in the past year (mean 1.8). Of these individuals, 80 had reported all of them (22 doctors, 58 nurses), 41 some of them ( 23 doctors, 18 nurses) and 37 none of them (25 doctors, 12 nurses); thus doctors were less likely to report injuries than nurses. Only $51 \%$ of those affected had reported all injuries. The principal reason for non-reporting was a low perceived risk of transmission of infection (Table 1). Almost everyone in the study (94\%) acknowledged the benefits of early reporting concerning themselves, but only $61 \%$ thought that early reporting would benefit the patient. $79 \%$ were aware that the Trust had a policy on reporting though not all had seen it.

\section{DISCUSSION}

The rate of needle-stick injury revealed by this small local survey is disturbing. It is higher than that reported elsewhere. ${ }^{5,6}$ Institutional reports, moreover, have been deemed to underestimate actual injuries by about $50 \% .7,8$ Although doctors and nurses are aware of the benefits of 
Table 1 Reasons for not reporting needle-stick injuries

\begin{tabular}{lrc}
\hline Reason for not reporting & Doctors & Nurses \\
\hline Very low risk of transmission at the time & $70.8 \%$ & $39.3 \%$ \\
I could not spare the time & $22.9 \%$ & $17.8 \%$ \\
I could not be bothered & $18.7 \%$ & $3.6 \%$ \\
Low incidence of HIV/Hep B/Hep C in my & $18.7 \%$ & $7.1 \%$ \\
$\quad$ patient group & & \\
Did not know I had to & $8.3 \%$ & $7.1 \%$ \\
Did not know how to & $8.3 \%$ & $7.1 \%$ \\
Afraid positive result would affect my career & $6.2 \%$ & - \\
Other & $16.7 \%$ & $17.8 \%$ \\
\hline
\end{tabular}

early reporting, a culture of silence persists. ${ }^{9}$ The exact reasons for under-reporting remain unclear. ${ }^{18}$ Doctors, who are less likely to report than nurses, may be more inclined to make their own risk assessment before deciding how to proceed. Workload pressures and time constraints are likely to cause both needle-stick injuries ${ }^{10,11}$ and underreporting. Our survey does not indicate whether the advent of safer needle devices, ${ }^{12-14}$ has lessened the risk of injury. Initial studies indicate these devices to be cost-effective, and introduction in some hospitals in the United States has become compulsory. ${ }^{15-17}$

Mandatory post-exposure testing of healthcare professionals, although theoretically simple, in practice presents complex moral, ethical and legal dilemmas. Those who become infected are at risk of being uncompensated and deprived of gainful employment. Unless specific infective incidents can be identified, neither employer nor insurance company is likely to be generous.

The responsibility for protection against lethal viral pathogens lies partly with the healthcare workers, who must handle sharps carefully ${ }^{18,19}$ and adhere to guidelines. The employer, in turn, has a duty to provide a safe environment, to educate all employees about the risk of viral transmission ${ }^{20}$ and to enforce reporting of all incidents. ${ }^{21,22}$ Simple, rapid, confidential access to postexposure tests must be made available. In the event of injury the onus of taking blood and getting consent from the involved patient should not lie with the healthcare professional. There must be a clear and adequate compensation policy. Occupationally acquired HBV and HIV infections require swift action in confidence and without prejudice. ${ }^{23}$

\section{REFERENCES}

1 A Safer Place to Work: Improving the Management of Health and Safety Risks to Staff in NHS Trusts. London: National Audit Office, 2003
2 Public Health Laboratory Services AIDS \& STD Centre. Occupational Transmission of HIV. London: PHLS 1999:73

3 Goldmann DAJ. Blood-borne pathogens and nosocomial infections. Allergy Clin Immunol 2002;110(2 suppl):S21-6

4 Goldberg D, Johnston J, Cameron S, et al. Risk of HIV transmission from patients to surgeons in the era of post-exposure prophylaxis. J Hosp Infect 2000;44:99-105

5 Gillen M, McNary J, Lewis J, et al. Sharps-related injuries in California healthcare facilities: pilot study results from the Sharps Injury Surveillance Registry. Infect Control Hosp Epidemiol 2003;24:113-21

$6 \mathrm{Ng} \mathrm{LN}$, Lim HL, Chan YH, Bin Bachok D. Analysis of sharps injury occurrences at a hospital in Singapore. Int J Nurs Pract 2002;8:274-81

7 Roy E, Robillard P. Underreporting of accidental exposures to blood and other body fluids in health care settings: an alarming situation. Adverse Exposure Prev 1995;1:11

8 Cato D, Mulhal BP. Needlestick injuries in health care professionals: continuing risk and under-reporting. Med J Aust 1994;161:285

9 Doebbeling BN, Vaughn TE, McCoy KD, et al. Percutaneous injury, blood exposure, and adherence to standard precautions: are hospitalbased health care providers still at risk? Clin Infect Dis 2003; 15;37:1006-13

10 Clarke SP, Sloane DM, Aiken LH. Effects of hospital staffing and organizational climate on needle stick injuries to nurses. Am J Publ Health 2002;92:1115-19

11 Clarke SP, Rockett JL, Sloane DM, Aiken LH. Organizational climate, staffing, and safety equipment as predictors of needle stick injuries and near-misses in hospital nurses. Am J Infect Control 2002;30:207-16

12 Alvarado-Ramy F, Beltrami EM, Short LJ, et al. A comprehensive approach to percutaneous injury prevention during phlebotomy: results of a multicenter study, 1993-1995. Infect Control Hosp Epidemiol $2003 ; 24: 82-5$

13 Asai T, Hidaka I, Kawashima A, et al. Efficacy of catheter needles with safeguard mechanisms. Anaesthesia 2002;57:572-7

14 Safer needles. AIDS Policy Law 1999;14:12

15 Peate WF. Preventing needle sticks in emergency medical system professionals. J Occup Environ Med 2001;43:554-7

16 Hatcher IB. Reducing sharps injuries among health care professionals: a sharps container quality improvement project. J Qual Improv 2002;28:410-14

17 Rabaud C, Zanea A, Mur JM, et al. Occupational exposure to blood: search for a relation between personality and behavior. Infect Control Hosp Epidemiol 2000;21:564-74

18 Stringer B, Infante-Rivard C, Hanley JA. Effectiveness of the handsfree technique in reducing operating theatre injuries. Occup Environ Med 2002;59:703-7

19 Wang $\mathrm{H}$, Fennie $\mathrm{K}$, He G, Burgess J, Williams AB. A training programme for prevention of occupational exposure to bloodborne pathogens: impact on knowledge, behaviour and incidence of needle stick injuries among student nurses in Changsha, People's Republic of China. J Adv Nurs 2003;41:187-94

20 Higher priority urged for needle stick prevention. Aids Alert 1998; 13:113-15

21 Sterling ML. Report of the Council on Scientific Affairs: preventing needle stick injuries in health care settings. Arch Intern Med 2001;161:929-36

22 Debnath D. Improving reporting of sharp injuries. Hosp Med 2000;61:852-4

23 Wright JG, McGeer A. Human immunodeficiency virus transmission between surgeons and patients in orthopaedic surgery. Clin Orthop 1993;297:272-81 